Article

\title{
A Study of the Mechanical Properties of Composite Materials with a Dammar-Based Hybrid Matrix and Two Types of Flax Fabric Reinforcement
}

\author{
Dumitru Bolcu $+\mathbb{D}$ and Marius Marinel Stănescu *,+(D) \\ Department of Mechanics, University of Craiova, 165 Calea Bucureşti, 200620 Craiova, Romania; \\ dbolcu@yahoo.com \\ * Correspondence: mamas1967@gmail.com; Tel.: +40-740-355-079 \\ + These authors contributed equally to this work.
}

Received: 7 July 2020; Accepted: 22 July 2020; Published: 24 July 2020

check for updates

\begin{abstract}
The need to protect the environment has generated, in the past decade, a competition at the producers' level to use, as much as possible, natural materials, which are biodegradable and compostable. This trend and the composite materials have undergone a spectacular development of the natural components. Starting from these tendencies we have made and studied from the point of view of mechanical and chemical properties composite materials with three types of hybrid matrix based on the Dammar natural hybrid resin and two types of reinforcers made of flax fabric. We have researched the mechanical properties of these composite materials based on their tensile strength and vibration behavior, respectively. We have determined the characteristic curves, elasticity modulus, tensile strength, elongation at break, specific frequency and damping factor. Using SEM (Scanning Electron Microscopy) analysis we have obtained images of the breaking area for each sample that underwent a tensile test and, by applying FTIR (Fourier Transform Infrared Spectroscopy) and EDS (Energy Dispersive Spectroscopy) analyzes, we have determined the spectrum bands and the chemical composition diagram of the samples taken from the hybrid resins used as a matrix for the composite materials under study. Based on the results, we have suggested that these composite materials could be used in different fields of activity.
\end{abstract}

Keywords: hybrid matrix; flax fabric; composite materials; mechanical properties; chemical structure

\section{Introduction}

The composite materials based on renewable raw materials from agriculture and biomass are more and more used, because these products significantly compensate for the use of fossil fuels and reduce the greenhouse gas emissions in comparison with the petrol-based traditional materials. However, including natural fibers in polymers comes with several challenges, such as excessive absorption of water and low thermal properties, which must be overcome in order to manufacture materials with properties comparable with the traditional composite materials.

The synthetic resins have the disadvantage of a restriction of processing due to the high viscosity at melting, phenomenon which occurs at injection molding, and the final product is hard to be recycled. This disadvantage can be removed by using a vegetal oil resin-based thermorigid-biological matrix, which, being biodegradable, does not require a polymerization process (see [1-3]). Bio-polymers are obtained from renewable resources and, during recent years, they have acquired a higher importance compared with petrol-based polymers (see [4]). Among the most used vegetal resins are Sandarac, Copal and Dammar. These natural resins are insoluble in water, but are mildly soluble in oil, alcohol, turpentine and partially in petrol. With certain organic solvents, they form solutions usable as coverage 
polish (see [5-9]). These polishes have been used since the Middle Ages by people with the purpose of embellishing and protecting paintings, musical instruments or furniture. A disadvantage for the natural varnishes is given by the fact that it cannot form viscous resins (see for example the works $[5,6]$ ). A solution to remove this disadvantage is to use hybrid resins obtained by combining more elements, out of which at least one is organic and at least one is synthetic. It must be mentioned that most tests to obtain such resins have taken place in the industry of polishes (see [5-7]). Hybrid resins represent an environment friendly alternative in comparison with synthetic resins.

Besides the hybrid resins, the use of natural reinforcing materials instead of synthetic fibers has developed very much with a view to manufacturing biodegradable composite materials (see $[10,11]$ ). In comparison with synthetic fibers, natural fibers are characterized by biodegradability and renewability. Among the most used natural fibers, the following can be mentioned: kenaf, hemp, flax, jute, henequen, pineapple leaves, sisal, wood, herbage, corn stem, coconut, etc. According to [1,12] the specific strength and specific moduli of some natural fibers are comparable with those of the glass fiber. Instead, the ultimate tensile strength, Young's modulus, density are lower in comparison with those of the glass fiber. The mechanical features, such as density, fiber diameter, tensile strength, Young's modulus, elongation at break, for natural fibers (flax, hemp, jute, kenaf, ramie, nettle, sisal, henequen, abaca, palm oil, cotton, coconut) and synthetic fibers (glass fiber, carbon, Kevlar) are found in [10-14].

Among these natural fibers, flax, due to its higher tensile properties, has been applied widely as reinforcement material for polymeric composites. Flax fibers have some advantages in comparison with glass fiber, because these are less dense, renewable, combustible and have a relatively low price. The composite materials reinforced with flax are considered next generation materials due to the structural applications in various industries and especially in the automotive industry (see [12-21]. Various other applications of composites reinforced with flax and their properties are registered by [22], and the composites reinforced with flax and hemp are presented by [23-25].

An important restriction to successfully using the flax fibers in sustainable composite applications is their high humidity absorption and the low dimensional stability. Moreover, the mechanical properties of flax fibers are also affected by manufacturing processes, such as retting, scutching, bleaching and spinning (see $[26,27]$. To remove these shortcomings, various surface treatments for fibers have been done, including the treatment with silane, benzoylation and peroxide, to improve mechanical performance. The effects of surface treatment for flax fibers with vinyl trimethoxy silane (VTMO) and anhydride maleic-polypropylene (MAPP) on the mechanical properties of flax composites/PP have been researched by [28]. MAPP treatment has been adequate to flax/PP composites from the point of view of tensile strength and impact. VTMO treatment has shown higher bending properties and less influence on the impact properties following the absorption of humidity. Remarkable differences in mechanical behavior were found between alkaline treated fiber composites and untreated fiber composites (see [29]). It was found that the fiber-matrix interface was only marginally influenced by alkaline treatment. The main difference between treated and untreated fibers was the presence, in the mass of untreated fibers, of agglomerations of fibers. The combined action of alkalization and mechanical stresses during melt mixing led to a uniform distribution of treated fibers that were more efficient in obtaining superior mechanical properties, in accordance with theoretical predictions.

Blending hybrid resins and natural fibers fabrics leads to obtaining some environment friendly composite materials. Composite materials reinforced with flax threads and flax fabrics, with a strengthened-soy matrix, have been prepared by [30] to compare the properties of tensile strength and bending. The composites reinforced with flax threads have had the highest tensile strength of $298 \mathrm{MPa}$ and a bending strength of $117 \mathrm{MPa}$, while the composites of flax fabrics have had a breaking point of $62 \mathrm{MPa}$ in the warp direction and $83 \mathrm{MPa}$ in the weft direction. The renewable epoxy resin resulted from vegetal oil is a potential substitute of the basic petrol resin in the flax composites used in applications for vehicle construction. Such composites are studies in [31-35], whereas [32] focuses on 
the influence of the architecture of fabrics on the mechanical properties of these composites. The tannin resin, a natural phenolic resin, reinforced with flax fibers, has been used to obtain some bodywork and dashboard elements for super-light electrical vehicles (see [36-38]. In the paper [39] composites based on tannin, reinforced with non-woven flax fibers have been manufactured and their mechanical properties have been studied. At the same time, Ref. [38,40] analyze the basic flax/tannin composites with four configurations of non-woven flax fibers and various angles of fabric layout.

Dammar, which is a resin obtained from trees from Dipterocarpaceae family from India and Eastern Asia, occupies a special place among the natural resins used. The studies performed on this resin have especially taken into consideration its chemical structure and chemical properties, presented in-depth in $[20,21]$. The resin mostly contains tetracyclic Dammarane skeletons, as well as pentacyclic oleanane, ursane and hopane derivatives. Also, it contains a small amount of sesquiterpenoid (C15). Dammar has been found to have an alcohol soluble part ( $\alpha$-resene) and an insoluble part ( $\beta$-resene). Dammar resin is known to be used as a component of certain drugs. In this respect, Ref. [41] has conducted a study on the continuous administration of the drug atenolol made of Dammar gum reticulated with biodegradable hydrogel composites based on polyacrylamide and zirconium. The reticulation process has been successfully synthesized, obtaining better properties for the polyacylamide Dammar gum, which are explained by the presence of an inorganic component in the zirconium mixture. The hydrogel properties (Dammar gum mixed with zironium iodoxalate) are analyzed by [42-44]. The samples were prepared to incorporate certain inorganic zirconium precipitates in a polymer mixture under vacuum conditions. The morphology and structure have been studied by using FTIR (Fourier transform infrared spectroscopy), SEM (Scanning Electron Microscopy) with EDS (Energy dispersive spectroscopy), X-ray diffraction data, Thermo gravimetric analysis, differential thermal analysis and differential thermo gravimetric analysis. In the end, we have found that hydrogel can be used for preferential removing of $P_{b}^{2-}$, in comparison with other metal ions, in solutions. Also, it has shown high chemical and thermal stability.

Studies concerning the mechanical behavior of natural resins are few. In [45], the mechanical features (tensile strength, percentage elongation and Young's modulus), water vapor transmission features and humidity absorption features for films of Dammar which contain or do not contain plasticizer have been studied. Ref. [46,47] study the method by which the addition of Dammar has contributed to the improvement of rigidity, elasticity modulus and hardness of a modified silicon. Studies referring to composite materials which have matrix and reinforcing material of natural materials are few. In [48], the mechanical properties of some composite materials obtained of hybrid resin based on Dammar reinforced with flax, cotton, hemp, wheat straw and bulrush are studied. In [49], the influence of some non-uniformities on the mechanical behavior of composite materials with Dammar-based matrix and reinforcing material of hemp fabric is presented.

There are no significant results regarding the mechanical properties of Dammar natural resin. This is due to the shape of the granules in which the Dammar resin is found (a shape that does not allow the making of samples to be subjected to the tensile test).

In this paper, we study some mechanical properties of some composite materials, which have as matrix three types of Dammar-based hybrid resins, and, separately, for each type of resin, we have used as reinforcing material two types of flax fabric.

\section{Used Materials and Equipment}

\subsection{Making the Samples}

The temperature of the environment in which we made the castings was $21-23^{\circ} \mathrm{C}$. All specimens were cut 10 days after pouring the plates.

Please note that the natural Dammar resin we used to make the hybrid resin was purchased from an authorized distributor (VITALNET MED SRL, Bucharest, Romania, see [50]), and the two 
types of flax fabric were purchased directly from the manufacturer (DINATEX SRL, Falticeni, Suceava, Romania, see [51]).

The natural Dammar resin is diluted with turpentine and if it is kept in closed recipients, it is remains liquid. That mixture is used for the protection of paintings (varnishes). The disadvantage is that the resin strengthening process is very long, even if it is applied in thin layers. Ref. [5-7] show that natural varnishes can create thick resins only in the presence of some synthetic components. We have removed this shortcoming by adding synthetic resin, together with the associated hardener.

During the first phase, we have cast three plates of resin.

We have done as follows:

1. we have mixed a volume ratio of $50 \%, 60 \%$ and respectively $70 \%$ of liquid Dammar with $50 \%, 40 \%$ and respectively $30 \%$ epoxy resin of Resoltech type 1050 and the associated hardener of Resoltech 1055 type;

2. in the end, to increase the volume ratio of Dammar from the obtained resins (and to increase the viscosity and implicitly to reduce the hardening time), we have added $10 \%$ Dammar powder of the total volume and we have mixed until homogenization.

Henceforth, the three types of obtained resin will be called hybrid resins of type 1, 2 and 3.

The properties of the epoxy resin (Resoltech 1050/Resoltech 1055) can be accessed from the webpage of the manufacturer (see [52]). The synthetic structure (epoxy resin and hardener) has been necessary to generate fast activation points for the polymerization process.

We have cut three sets of ten samples from the cast plates and they will be labelled with: 1.1-10 for samples of hybrid resin of type 1; 2.1-10 for samples of hybrid resin of type 2; 3.1-10 for samples of hybrid resin of type 3 . The cutting of samples has been done 10 days later than the plates casting. The samples sizes have been: length of $250 \mathrm{~mm}$, width $25 \mathrm{~mm}$ and thicknesses have been $6.1 \mathrm{~mm}$ and $6.2 \mathrm{~mm}$. These dimensions are used in the tensile tests, which are done according to ASTM D3039 (see [53]). The density of samples is between $1.04-1.06 \mathrm{~g} / \mathrm{cm}^{3}$.

In Figure 1, a sample from each set of hybrid resin is presented.

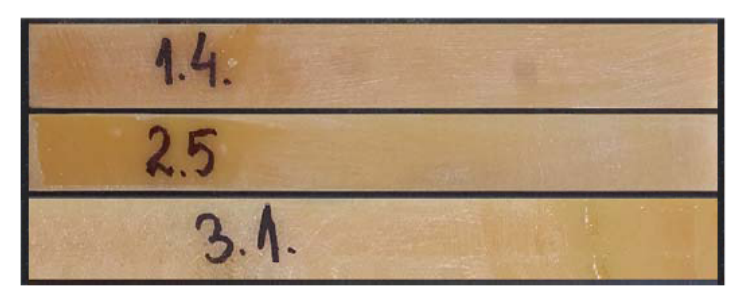

Figure 1. Samples of each set of hybrid resin.

During the second phase, we have manufactured composite materials by reinforcement with five layers of two types of flax fabric from the hybrid resins. The flax fibers properties are (see for example $[1,54,55]$ ): density $1.5 \mathrm{~g} / \mathrm{cm}^{3}$, elasticity modulus $27-39 \mathrm{GPa}$, tensile strength 345-1100 MPa, elongation at break 2.7-3.2\%. When making the composite plates we applied a uniform pressure of $27,000 \mathrm{~N} / \mathrm{m}^{2}$.

For the first type, 12 layers of mixture with $20 \%$ cotton and $80 \%$ flax have been placed, the fabric with the specific mass of $240 \mathrm{~g} / \mathrm{m}^{2}$. The obtained composites have a density of $1.17-1.18 \mathrm{~g} / \mathrm{cm}^{3}$, and the mass ratios of resin in the manufactured plates are presented in Table 5.

For the second type, 20 layers of mixture with $40 \%$ cotton and $60 \%$ flax have been placed, the fabric with a specific mass of $160 \mathrm{~g} / \mathrm{m}^{2}$. The obtained composites have a density of $1.20-1.21 \mathrm{~g} / \mathrm{cm}^{3}$, and the mass ratios of resin in the manufactured plates are presented in Table 6.

The two types of flax fabric are presented in Figure 2. 


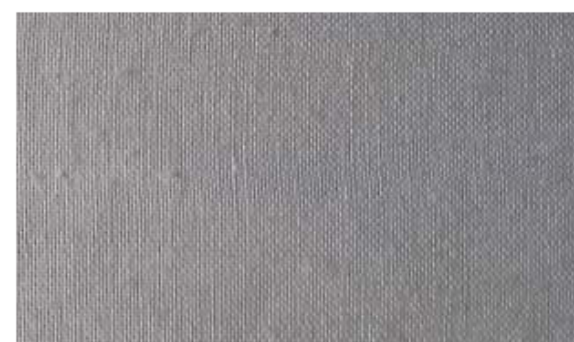

a)

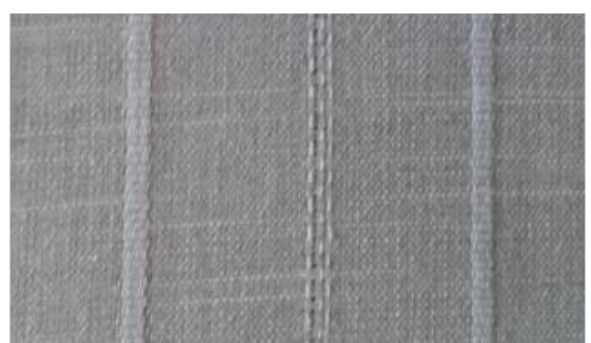

b)

Figure 2. Used flax fabrics: (a) 20\% cotton and 80\% flax; (b) $40 \%$ cotton and $60 \%$ flax.

We can see that in the composites reinforced with the same type of fabric, no significant differences of density exist when the Dammar ratio is modified in the used hybrid resin. The composites reinforced with the second type of fabric have a higher density than those reinforced with the first type of fabric, which can be explained by the differences of volume ratio and by the differences of density between fabrics.

We have also cut sets of ten samples from the plates of composite materials. The samples have had a length of $250 \mathrm{~mm}$, width of $25 \mathrm{~mm}$ and thickness between $6.2 \mathrm{~mm}$ and $6.3 \mathrm{~mm}$, for the samples reinforced with first type of fabric and between $6.1 \mathrm{~mm}$ and $6.2 \mathrm{~mm}$ for samples reinforced with second type of fabric. For the study of vibrations, samples with a length of $300 \mathrm{~mm}$ and width of $25 \mathrm{~mm}$ have been cut from plates of composite materials.

Table 1 presents centralized the constituent elements of the composite materials made.

Table 1. The constituents of the manufactured composite materials.

\begin{tabular}{ccccc}
\hline $\begin{array}{c}\text { Hybrid Resin } \\
\text { Type }\end{array}$ & $\begin{array}{c}\text { Dammar Volume } \\
\text { Ratio }\end{array}$ & $\begin{array}{c}\text { Fabric } \\
\text { Type }\end{array}$ & $\begin{array}{c}\text { Number of } \\
\text { Layers }\end{array}$ & $\begin{array}{c}\text { Mass Ratio } \\
\text { of Hybrid Resin }\end{array}$ \\
\hline \multirow{2}{*}{1} & $50 \%$ & $80 \%$ flax and 20\% cotton & 12 & 0.52 \\
\hline \multirow{2}{*}{2} & $60 \%$ & $80 \%$ flax and 40\% cotton & 20 & 0.52 \\
\hline \multirow{2}{*}{3} & \multirow{2}{*}{$70 \%$} & $60 \%$ flax and 20\% cotton & 12 & 0.54 \\
& & $80 \%$ flax and 20\% cotton & 12 & 0.51 \\
\hline
\end{tabular}

\subsection{Devices Used for Tests}

Both the samples of hybrid resin and those of composite materials have been subject to tensile test, which has been done in accordance with the provisions of ASTM D3039. We have used the machine for mechanical tests LLOYD Instruments Lrx PLU, with maximum force of $2.5 \mathrm{kN}$, equipped with the analysis soft NEXYGEN (technical features can be found on the web page of the manufacturer, see [56]).

The traction speed was $2.5 \mathrm{~mm} / \mathrm{min}$.

The mechanical properties obtained based on this test have been: characteristic curve, tensile strength $R_{m}[\mathrm{MPa}]$, percentage elongation at break $A$ [\%] and elasticity modulus $E$ [MPa].

The FTIR analysis has been performed by a portable system of IdentifyIR type (equipped with the ChemAssist soft). It complied with ASTM E168 and E1252 (see [57,58]). The size of the used sample has been under $5 \mu \mathrm{L}$ or $100 \mu \mathrm{m}$. Moreover, the equipment has been provided with ATR spectral libraries for detection Aldrich/Smiths. All the technical features of this system can be found on the web page of the manufacturer (see [59]).

The SEM-EDS analysis has been done with an electronic microscope Hitachi model S3400N-type $\mathrm{N}$, equipped with EDX Oxford Instruments X-act, with traditional cathode (see [60] with the technical specifications given by the manufacturer). Moreover, we mention that for the EDS analysis ASTM E1508 was complied with (see [61]). 
For the study of vibrations, the following measurement device has been used: data acquisition system SPIDER 8, connected by USB to a notebook; data acquisition set done by CATMAN EASY soft, which has connected the two entities; signal conditioner NEXUS 2692-A-0I4 connected to the SPIDER 8 system; accelerometer with sensitivity $0.04 \times 10^{-12} \mathrm{C} / \mathrm{ms}^{-2}$, connected to signal conditioner.

\section{Results}

Furthermore, by representative sample of a set we will understand a sample with average values of the studied mechanical properties.

\subsection{Experimental Results for the Studied Hybrid Resin}

In Figure 3, the tensile test equipment for a sample of hybrid resin is presented.

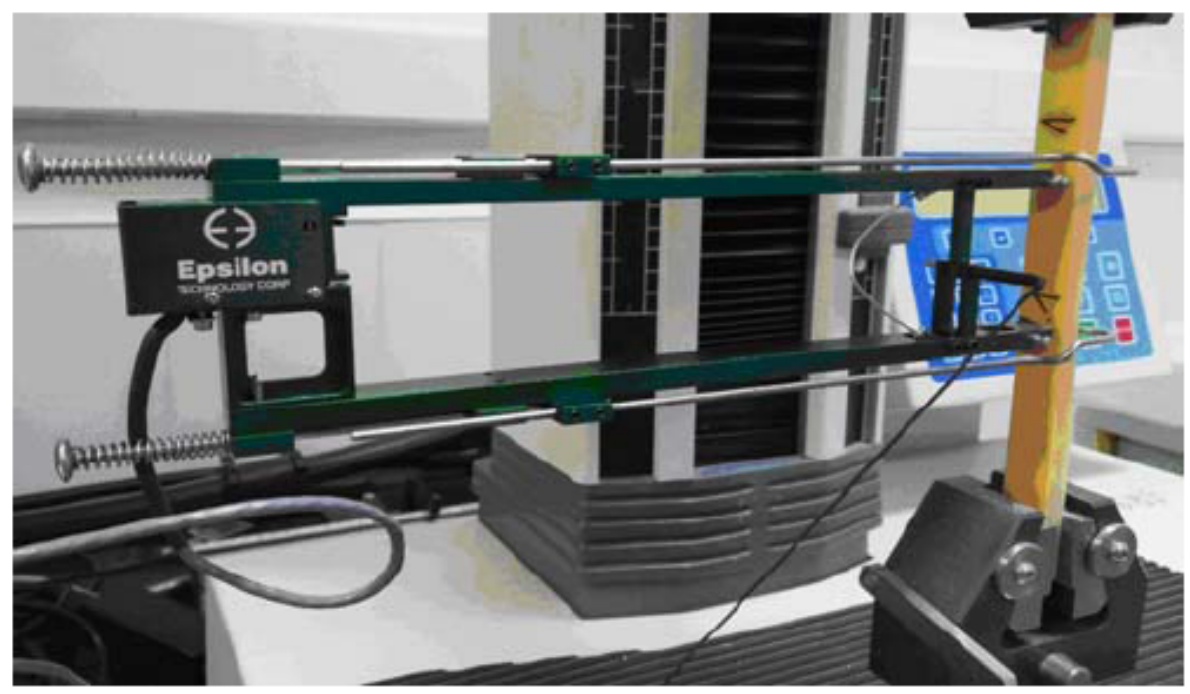

Figure 3. The tensile test equipment for a sample of hybrid resin.

The characteristic curves for a representative sample of each set of samples from the obtained hybrid resins are presented in the Figure 4.

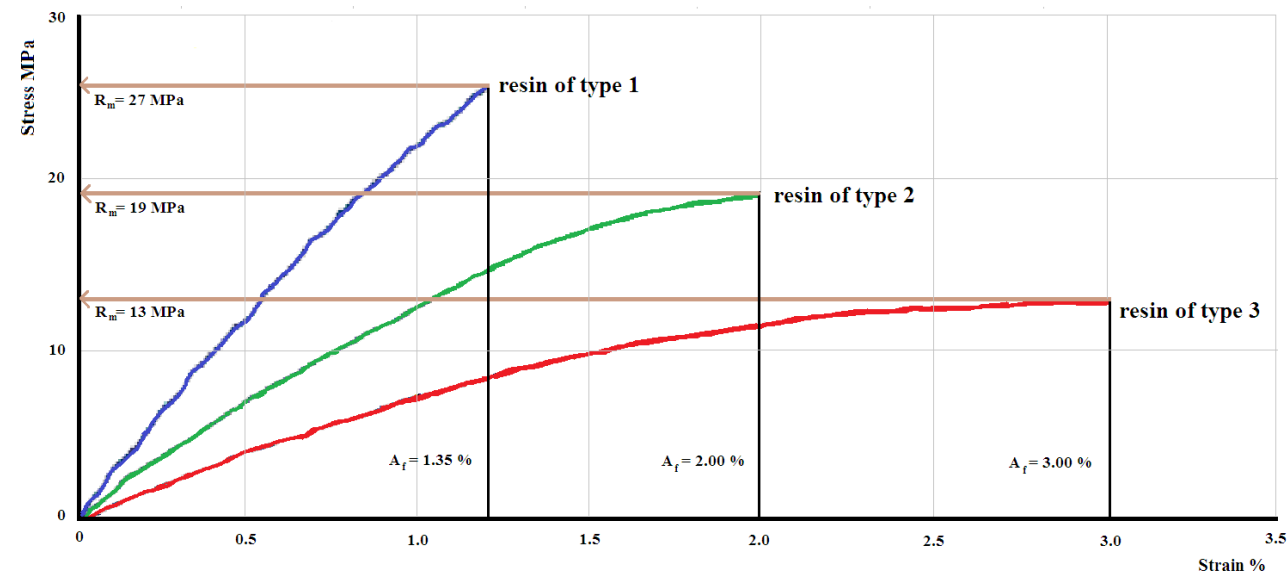

Figure 4. Characteristic curves for a representative sample of each set of samples from the obtained hybrid resins.

The experimental results for sets of samples of hybrid resin are presented in Table 2. 
Table 2. The mean value with the standard deviation for elasticity modulus, tensile strength and elongation at break for samples of the 3 types of hybrid resin.

\begin{tabular}{cccc}
\hline $\begin{array}{c}\text { Type of } \\
\text { Hybrid Resin }\end{array}$ & $\begin{array}{c}\text { Elasticity Modulus } \\
\boldsymbol{E}\left[\mathbf{N} / \mathbf{m m}^{2}\right]\end{array}$ & $\begin{array}{c}\text { Tensile Strength } \\
\boldsymbol{R}_{\boldsymbol{m}}[\mathbf{M P a}]\end{array}$ & $\begin{array}{c}\text { Elongation at Break } \\
\boldsymbol{A}[\%]\end{array}$ \\
\hline 1 & $3077( \pm 92)$ & $25.5( \pm 1.5)$ & $1.4( \pm 0.08)$ \\
2 & $2444( \pm 70)$ & $19( \pm 1)$ & $1.96( \pm 0.07)$ \\
3 & $1798( \pm 45)$ & $13( \pm 1)$ & $2.95( \pm 0.1)$ \\
\hline
\end{tabular}

We notice an important modification of the mechanical behavior, materialized by a change in the characteristic curve. If, in the case of 50\% Dammar natural resin samples the characteristic curve is practically linear, in the case of the other types of samples we observe the occurrence of a nonlinearity area, specific plastic behavior. These nonlinearities appear during specific deformations higher than $1.5 \%$, being more obvious in the case of $70 \%$ Dammar (which have the highest specific deformations). This phenomenon can be explained by the fact that the resins, even in solid state, have a rheological behavior characterized by viscosity. Due to external stresses, a low viscosity leads to significant deformations. Dammar resin diluted with turpentine remains liquid, so it has a low viscosity. Solidification occurs by mixing with synthetic resin. We found that the viscosity of the hybrid resin obtained decreases with increasing volume ratio of Dammar. Therefore, at the same external load, the deformations of the hybrid resin by $70 \%$ Dammar are higher than the deformations of the hybrid resin by $60 \%$, respectively $50 \%$ volume ratio of Dammar. In-depth studies on the composition and chemical properties of the hybrid resin based on Dammar (with various volume ratio) were performed in the paper [62].

In Figure 5, we present the FTIR analysis of a specimen of hybrid resin (specimen from type 2) and of the same re-tested specimen. The infrared spectrum, characteristic bands and a list of peaks seen between $4000-650 \mathrm{~cm}^{-1}$ are presented. This spectrum diagram is automatically plotted by the analysis system software.

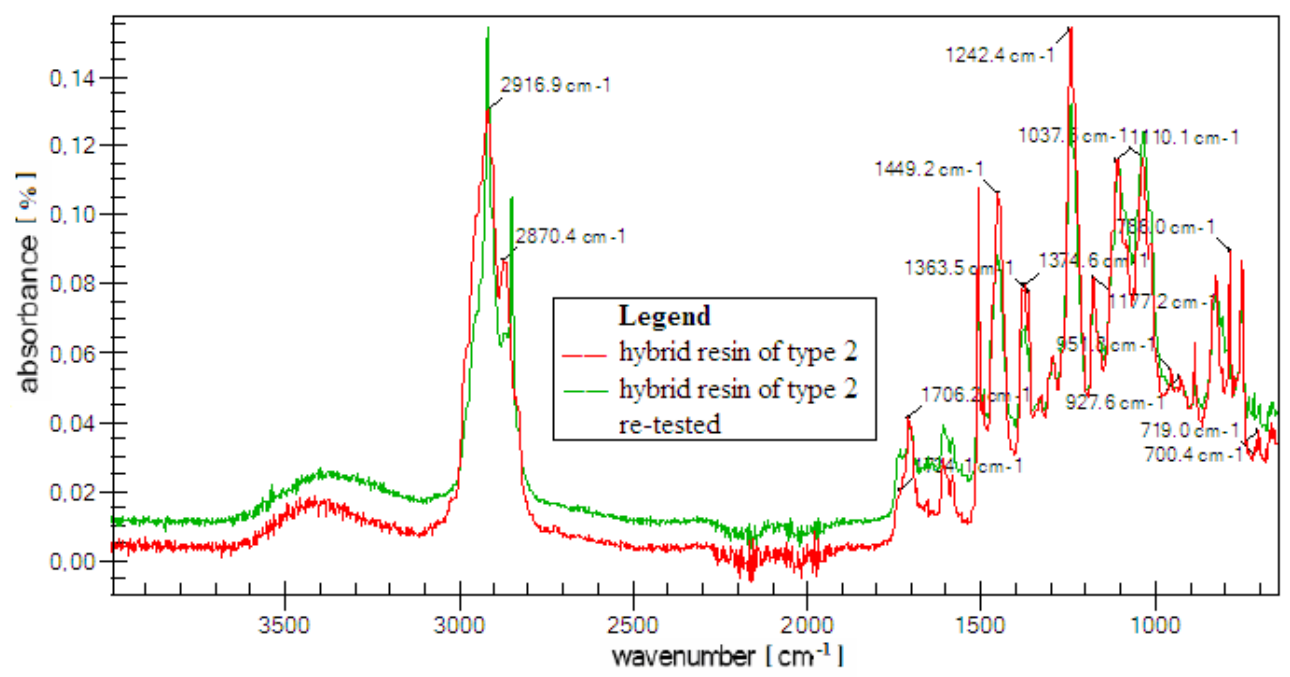

Figure 5. FTIR analysis of a specimen of hybrid resin (specimen from type 2) and of the same re-tested specimen.

Based on the diagram (and the peak list) two functional groups can be seen:

1. Ketene cumulated double bonds $\left(\mathrm{CH}_{2}=\mathrm{C}=\mathrm{O}\right)$, which are substance with cumulated carbonyl and carbon-carbon double bonds;

2. nitrogen double bond, known as Nitrite ion $\left(\mathrm{NO}_{2}^{-}\right)$and which contains nitrogen in a relatively unstable oxidation condition. 
The FTIR analysis equipment is equipped with Aldrich/Smiths ATR spectral libraries that can automatically identify a maximum of 10 volatile organic compounds in the structure of the analyzed resin. In Table 3, we present 10 volatile compounds identified in the chemical structure of hybrid resin of type 2 .

Table 3. 10 volatile compounds identified in the chemical structure of hybrid resin of type 2 .

\begin{tabular}{ccc}
\hline $\begin{array}{c}\text { Current } \\
\text { Number }\end{array}$ & Spectrum & $\begin{array}{c}\text { Aldrich/Smiths Detection ATR } \\
\text { Special Libraries }\end{array}$ \\
\hline 1 & 0.7628 & Vetiver (Natural Essential Oil) \\
2 & 0.7563 & Geranium algerie; Essence \\
3 & 0.7557 & Geranium bourbon (Natural Essential Oil) \\
4 & 0.7407 & Patchouli (Natural Essential Oil) \\
5 & 0.7333 & Dammar Gum \\
6 & 0.7270 & Vetiver java (Natural Essential Oil) \\
7 & 0.7002 & Bergamot (Natural Essential Oil) \\
8 & 0.6988 & Peppermint oil \\
9 & 0.6917 & Dinonylnaphthalenesulfonic acid (in kerosene) \\
10 & 0.6900 & Lavandin (Natural Essential Oil) \\
\hline
\end{tabular}

Based on the EDS analysis of a specimen of hybrid resin of type 2, taken from the samples of 2.x type, in Figure 6 we show the diagram of the chemical composition obtained at an intensity of $15 \mathrm{keV}$.

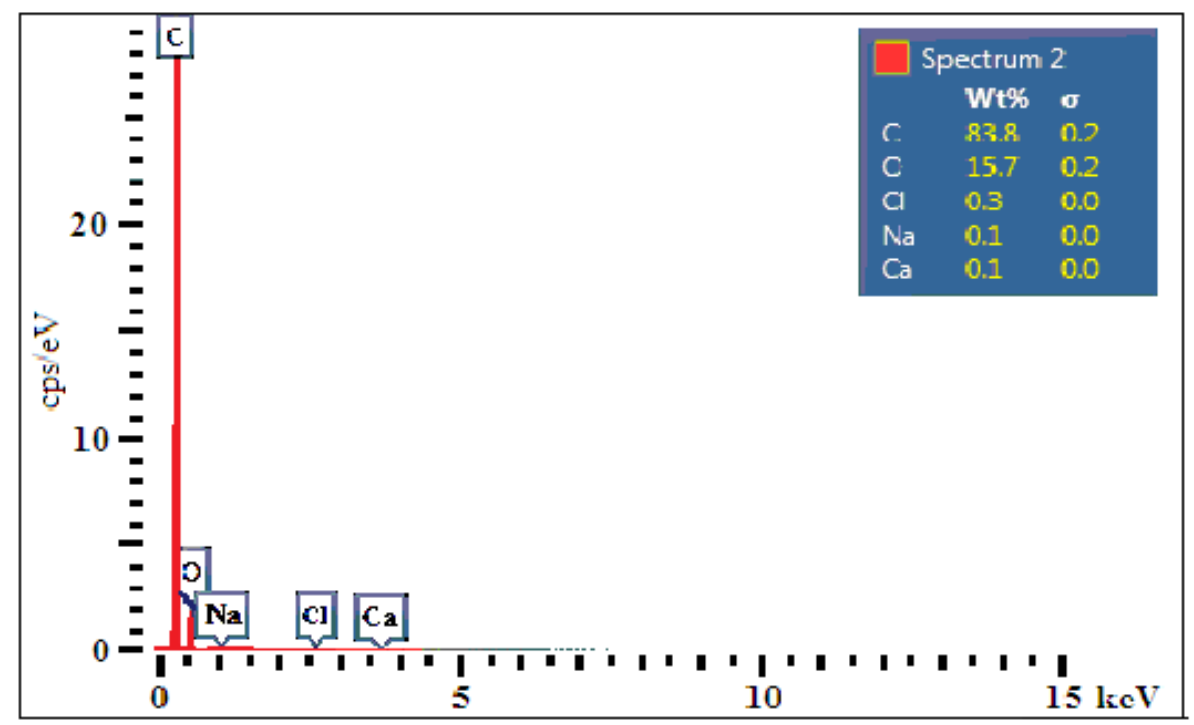

Figure 6. EDS analysis diagram of the chemical structure of a specimen of hybrid resin of type 2, taken from sample 2.x., obtained at an intensity of $15 \mathrm{keV}$.

In Table 4, based on the EDS analysis, we present the chemical structure of a specimen of hybrid resin of type 2, taken from sample 2.x. This structure is expressed by weight concentration, atomic concentration and number of atoms of each element.

Table 4. Chemical structure of a specimen of hybrid resin sample of type 2, taken from sample 2.x.

\begin{tabular}{cccccc}
\hline $\begin{array}{c}\text { Element } \\
\text { Number }\end{array}$ & $\begin{array}{c}\text { Element } \\
\text { Symbol }\end{array}$ & $\begin{array}{c}\text { Element } \\
\text { Name }\end{array}$ & $\begin{array}{c}\text { Atomic } \\
\text { Weight }\end{array}$ & $\begin{array}{c}\text { Weight } \\
\text { Conc. } \\
{[\%]}\end{array}$ & $\begin{array}{c}\text { Atomic } \\
\text { Conc. } \\
{[\%]}\end{array}$ \\
\hline 6 & $\mathrm{C}$ & Carbon & 12 & 83.8 & 87.51 \\
8 & $\mathrm{O}$ & Oxygen & 16 & 15.7 & 12.29 \\
17 & $\mathrm{Cl}$ & Chlorine & 35.5 & 0.3 & 0.11 \\
11 & $\mathrm{Na}$ & Sodium & 23 & 0.1 & 0.06 \\
20 & $\mathrm{Ca}$ & Calcium & 40 & 0.1 & 0.03 \\
\hline
\end{tabular}


We have used a total number of atoms equal with $48 \times 10^{23}$ approximately.

As in the paper [48], after the analysis of chemical concentrations in the three types of hybrid resin, we can conclude that:

- for Carbon, a decrease in the Atomic Concentration and the Weight Concentration is registered as the volume ratio of Dammar increases;

- for Oxygen, an increase in the Atomic Concentration and the Weight Concentration is registered as the volume ratio of Dammar increases.

\subsection{Experimental Results for the Studied Composite Materials}

The samples manufactured from composite materials reinforced with flax fabric have been subject to the tensile test. Figures 7-9 show the characteristic curves for composite materials with matrix of the three types of hybrid resin and which have been reinforced with the first type of flax fabric.

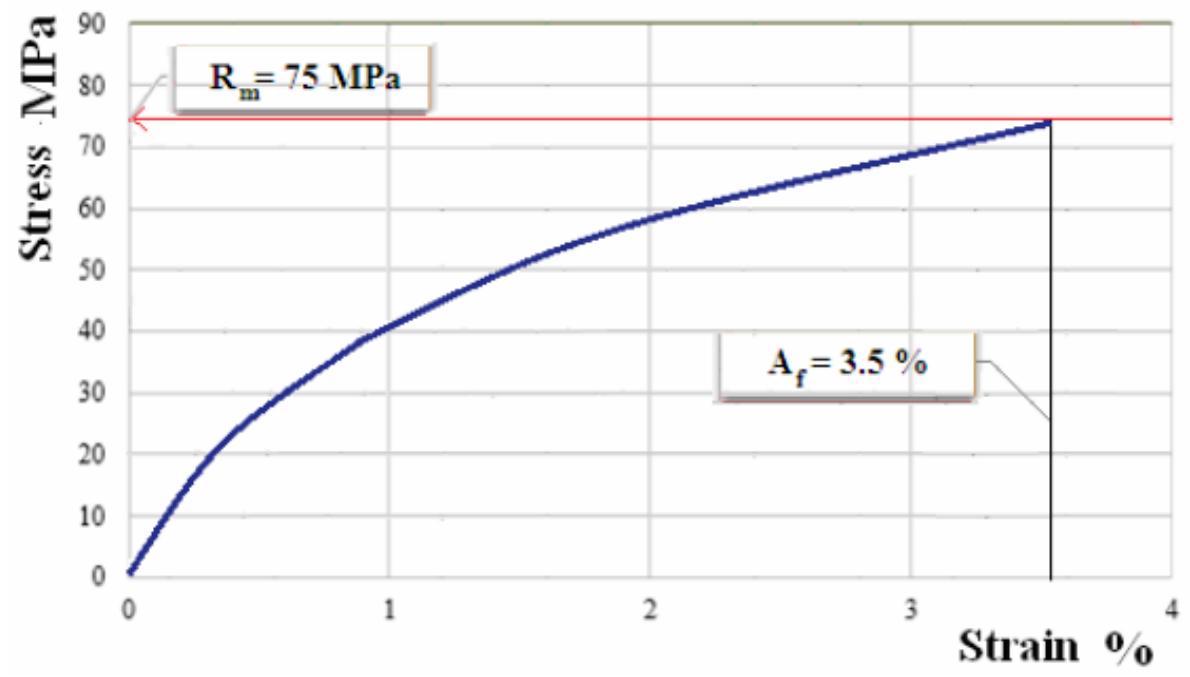

Figure 7. Characteristic curve for sample of composite material with matrix of hybrid resin of type 1, reinforced with fabric of first type.

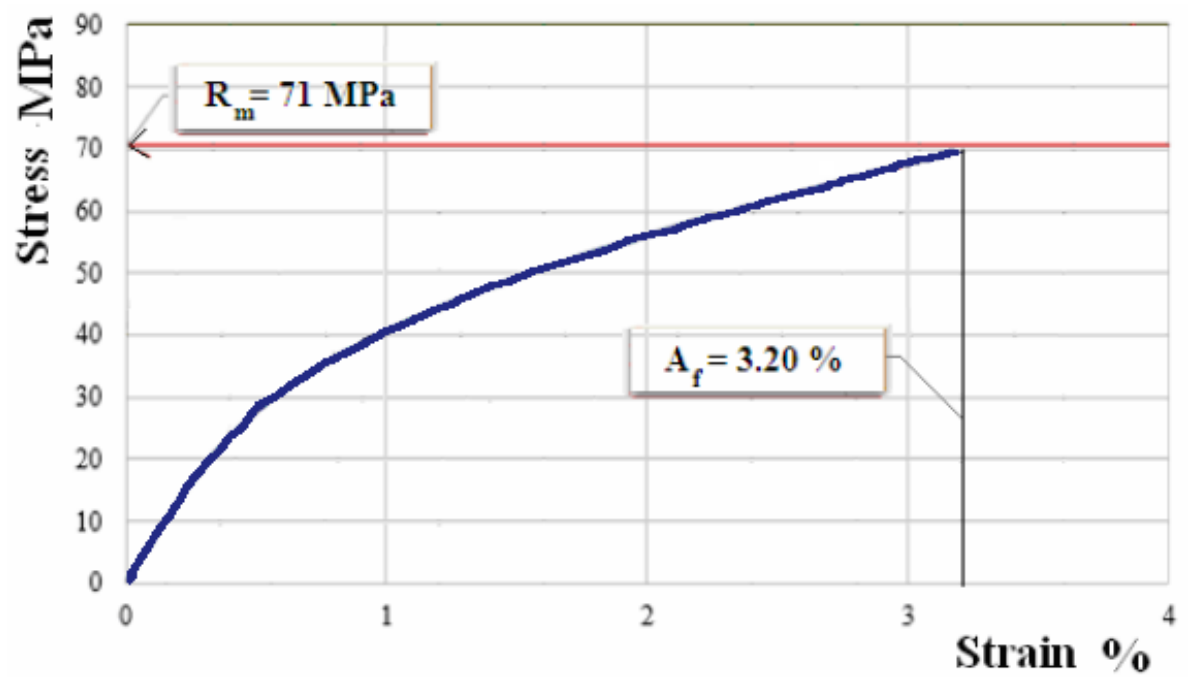

Figure 8. Characteristic curve for sample of composite material with matrix of hybrid resin of type 2, reinforced with fabric of first type. 


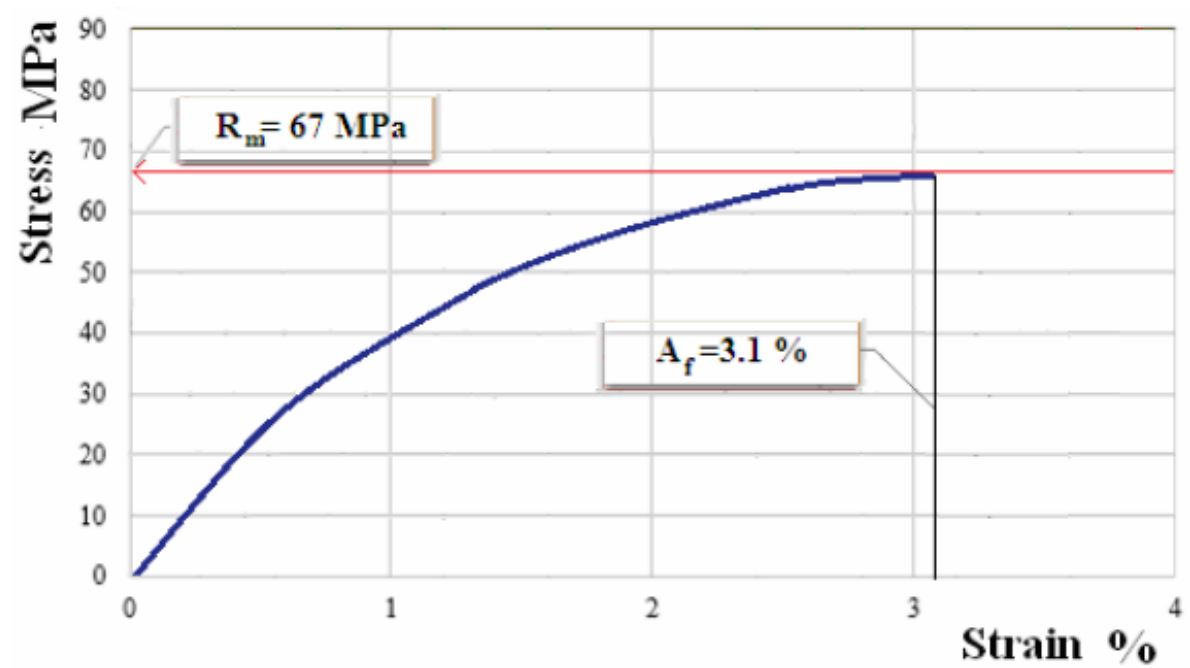

Figure 9. Characteristic curve for sample of composite material with matrix of hybrid resin of type 3, reinforced with fabric of first type.

The experimental results for sets of samples from composite materials with matrix of three types of hybrid resin, reinforced with first type of flax fabric, are presented in Table 5.

Table 5. The mean value with the standard deviation for elasticity modulus, tensile strength and elongation at break for composites with matrix of hybrid resin of type 1,2 and 3, reinforced with the first type of flax fabric.

\begin{tabular}{cccccc}
\hline $\begin{array}{c}\text { Type of } \\
\text { Hybrid Resin }\end{array}$ & $\begin{array}{c}\text { Thickness of } \\
\text { Sample } \\
{[\mathbf{m m}]}\end{array}$ & $\begin{array}{c}\text { Mass Ratio } \\
\text { of Hybrid Resin }\end{array}$ & $\begin{array}{c}\text { Elasticity } \\
\text { Modulus } \\
\boldsymbol{E}\left[\mathbf{N} / \mathbf{m m}^{2}\right]\end{array}$ & $\begin{array}{c}\text { Tensile Strength } \\
\boldsymbol{R}_{\boldsymbol{m}}[\mathrm{MPa}]\end{array}$ & $\begin{array}{c}\text { Elongation } \\
\text { at Break } \\
\boldsymbol{A}[\%]\end{array}$ \\
\hline 1 & 6.3 & 0.52 & $5340( \pm 50)$ & $73.5( \pm 1.5)$ & $3.4( \pm 0.1)$ \\
2 & 6.3 & 0.54 & $5180( \pm 40)$ & $70.5( \pm 1.5)$ & $3.28( \pm 0.08)$ \\
3 & 6.2 & 0.50 & $5005( \pm 55)$ & $67( \pm 1)$ & $3.2( \pm 0.1)$ \\
\hline
\end{tabular}

Figures 10-12 show the characteristic curves for composite materials with matrix of the three types of hybrid resin and which have been reinforced with the second type of flax fabric.

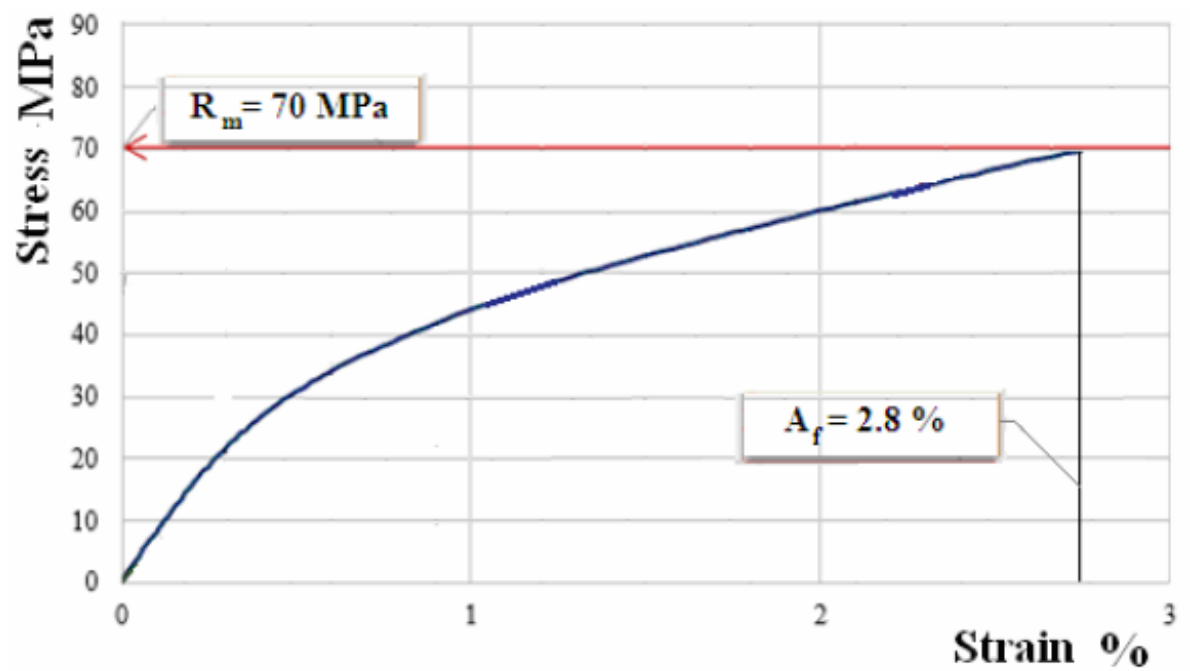

Figure 10. Characteristic curve for sample of composite material with matrix of hybrid resin of type 1, reinforced with the second type of fabric. 


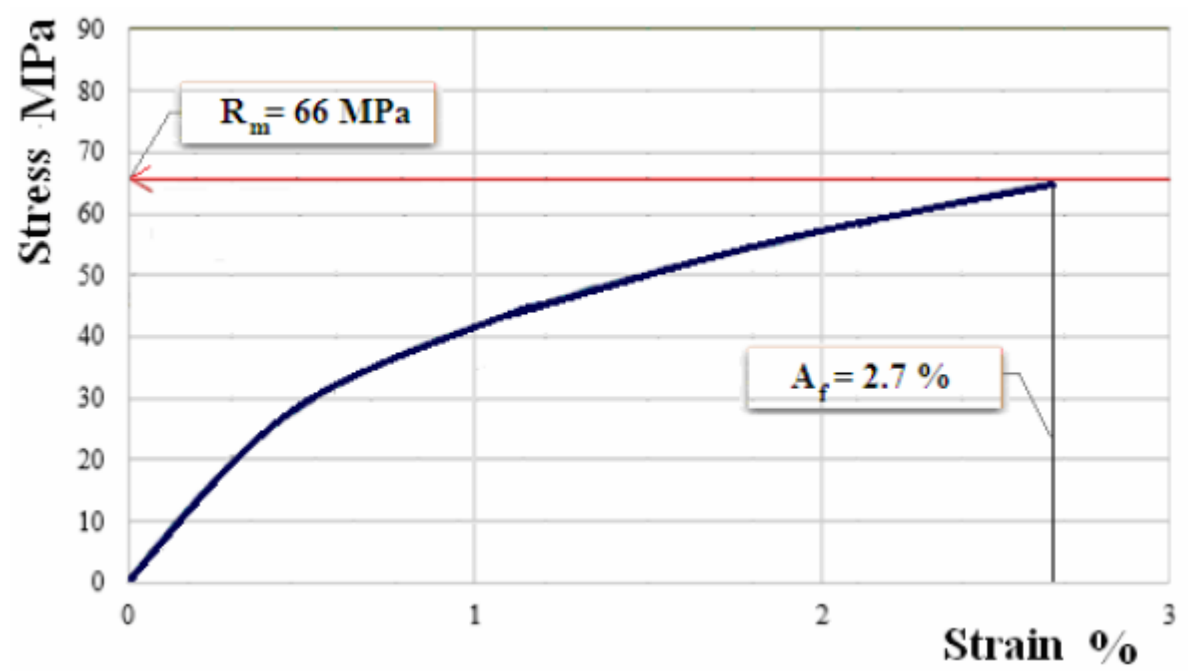

Figure 11. Characteristic curve for sample of composite material with matrix of hybrid resin of type 2, reinforced with the second type of fabric.

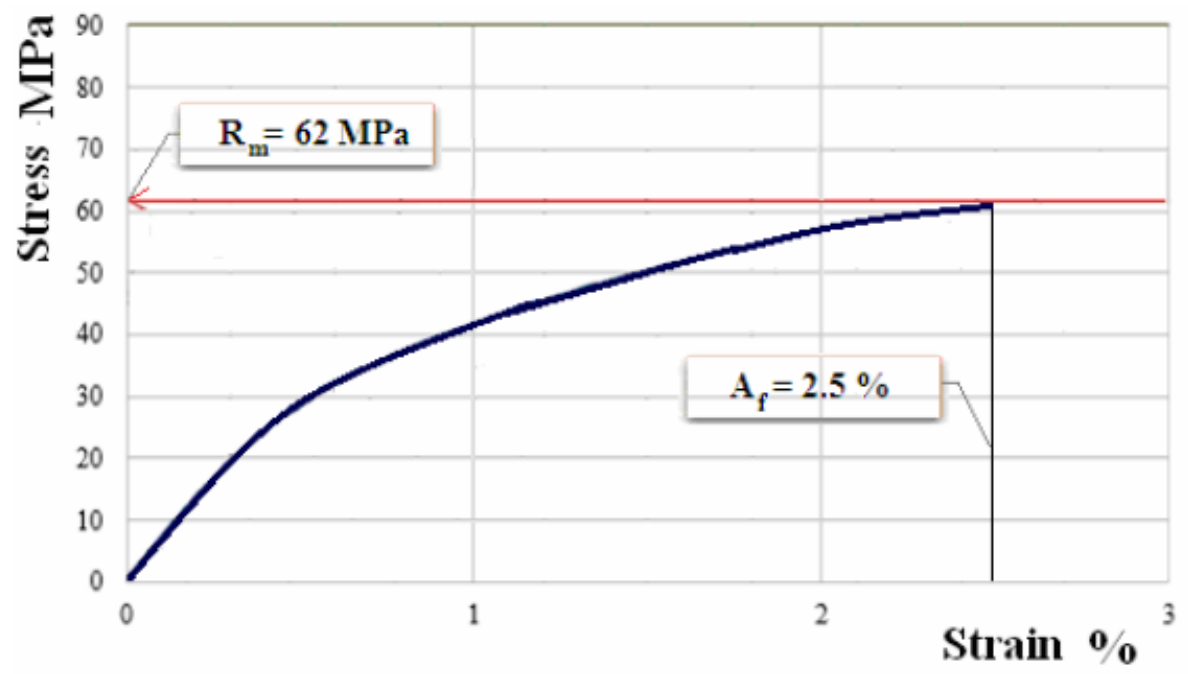

Figure 12. Characteristic curve for sample of composite material with matrix of hybrid resin of type 3 , reinforced with the second type of fabric.

The experimental results for the sets of samples of composite materials with matrix of the three types of hybrid resin, reinforced with the second type of flax fabric, are presented in Table 6.

Table 6. The mean value with the standard deviation for elasticity modulus, tensile strength and elongation at break for composites with matrix of hybrid resin of type 1,2 and 3, reinforced with second type of flax fabric.

\begin{tabular}{cccccc}
\hline $\begin{array}{c}\text { Type of } \\
\text { Hybrid Resin }\end{array}$ & $\begin{array}{c}\text { Thickness of } \\
\text { Sample } \\
{[\mathbf{m m}]}\end{array}$ & $\begin{array}{c}\text { Mass Ratio } \\
\text { of Hybrid Resin }\end{array}$ & $\begin{array}{c}\text { Elasticity } \\
\text { Modulus } \\
\boldsymbol{E}\left[\mathbf{N} / \mathbf{m m}^{2}\right]\end{array}$ & $\begin{array}{c}\text { Tensile Strength } \\
\boldsymbol{R}_{\boldsymbol{m}}[\mathrm{MPa}]\end{array}$ & $\begin{array}{c}\text { Elongation } \\
\text { at Break } \\
\boldsymbol{A}[\%]\end{array}$ \\
\hline 1 & 6.2 & 0.52 & $4890( \pm 20)$ & $69( \pm 1)$ & $2.82( \pm 0.08)$ \\
2 & 6.1 & 0.51 & $4790( \pm 50)$ & $65.5( \pm 1.5)$ & $2.70( \pm 0.05)$ \\
3 & 6.1 & 0.52 & $4720( \pm 40)$ & $62( \pm 1)$ & $2.58( \pm 0.08)$ \\
\hline
\end{tabular}

By comparison, composites made with the two types of flax fabrics have similar behaviors. However, composites reinforced with the first type of fabric have a breaking strength with 4.5-5 MPa higher than composites reinforced with the second type of fabric. In addition, for the modulus of elasticity the conclusion is similar. Composites reinforced with the first type of fabric have a 
modulus of elasticity with 285-450 MPa higher than composites reinforced with the second type of fabric. These differences arise from variations in the properties and distribution of flax fibers in the fabric, respectively.

In Figure 13, we present the image of the breaking area for a representative sample of the set of composite materials with matrix of hybrid resin of type 2 and reinforcing material of the first type of flax fabric (a), respectively the second type of flax fabric (b).

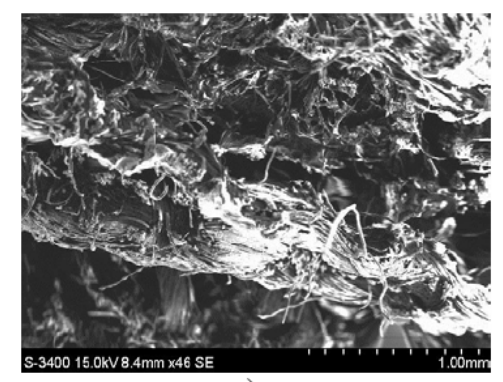

a)

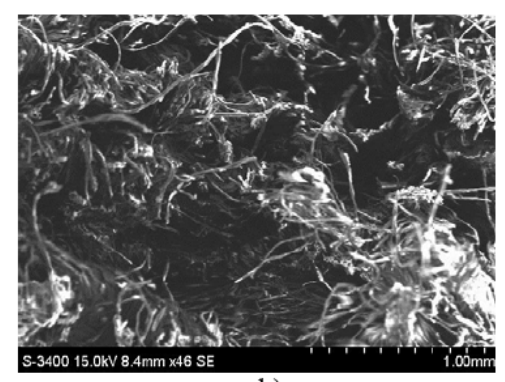

b)

Figure 13. Image of the breaking area for a representative sample of the set of composite materials with matrix of hybrid resin of type 2 and reinforcing material of the first type of flax fabric (a), respectively second type of flax fabric (b).

The studies on the vibrations of bars made of composite materials are based on models of various deformation theories that take into account shearing and are adapted so as to evaluate the static and dynamic characteristics of bars. Such a model is the Rayleigh model which considers the rotational inertia of the bar section. A more complex model is the Timoshenko model, which considers deformations due to shearing stress as well. This model underlies the "first order shear deformation theory", symbolized by FSDT. All these models consider that a plane and normal section on the average fiber before deformation stays plane without keeping the specified perpendicularity. The limits of the elementary theory and FDST have required the introduction of higher order shear deformation theories, symbolized HSDT. The main differences between the suggested models are generated by the functions used for ascertaining the deviations from the plane character of the bar section submitted to (polynomial, trigonometric, deformation hyperbolic) deformation. [63] compares the results obtained with the help of this theory.

In reality, due to internal friction and interaction with the air, all vibrations are damped. A general study conducted by [64] presents three mechanisms of energy dissipation. The first introduces the so-called external or viscous damping; however, for this mechanism all the modal amplitudes are damped at the same ratio, contrary to experience. The second mechanism considers that the damping force is proportional to the bending speed, whereas the third mechanism considers that the damping ratios of the specific vibration modes depend proportionally on the square of the frequency. A good number of articles investigate the various aspects and mechanisms of this phenomenon and the influence on vibration behavior of different composite materials (see [65-71]).

We have experimentally determined the damping coefficient and natural frequency for samples of composite materials having as matrix the three types of hybrid resin and reinforced, separately, with the two types of flax fabric. The studied samples have been embedded at one head, and the measurement has been done at the free head. The free length of samples has been $150 \mathrm{~mm}, 175 \mathrm{~mm}$, $200 \mathrm{~mm}, 225 \mathrm{~mm}$ and $250 \mathrm{~mm}$.

In Figure 14, we present the record of vibrations (natural frequency and damping factor) in a sample of composite material with matrix of hybrid resin of type 2, reinforced with the first type of flax fabric, for a free length of $200 \mathrm{~mm}$. 


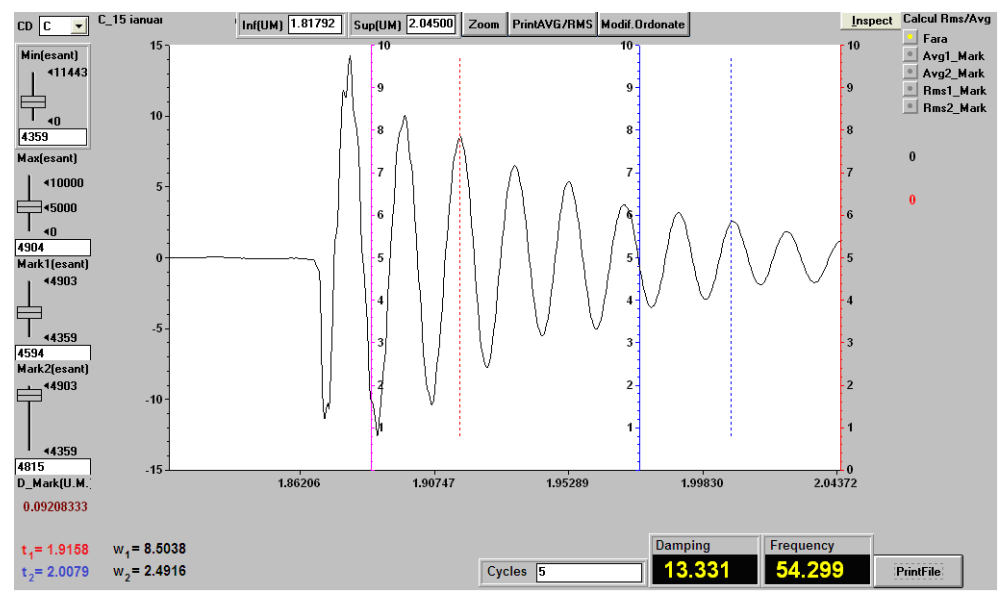

Figure 14. Registration of vibrations (natural frequency and damping factor) at a sample of hybrid resin of type 2, reinforced with first type of flax fabric, for a free length of $200 \mathrm{~mm}$.

In Table 7, we present the behavior under vibrations of samples from materials for composites with matrix of hybrid resin of type 1, 2 and 3, reinforced with first type of flax fabric. The presented values represent the arithmetic mean for three measurements.

Table 7. Behavior under vibrations of samples from composites with matrix of hybrid resin of type 1, 2 and 3 , reinforced with the first type of flax fabric.

\begin{tabular}{|c|c|c|c|c|c|c|}
\hline \multirow{2}{*}{$\begin{array}{c}\text { Free } \\
\text { Length } \\
{[\mathrm{mm}]}\end{array}$} & \multicolumn{2}{|c|}{$\begin{array}{c}\text { Composite Material with } \\
\text { Hybrid Resin of Type } 1\end{array}$} & \multicolumn{2}{|c|}{$\begin{array}{l}\text { Composite Material with } \\
\text { Hybrid Resin of Type } 2\end{array}$} & \multicolumn{2}{|c|}{$\begin{array}{c}\text { Composite Material with } \\
\text { Hybrid Resin of Type } 3\end{array}$} \\
\hline & $\begin{array}{l}\text { Frequency } \\
\quad v[\mathrm{~Hz}]\end{array}$ & $\begin{array}{l}\text { Damping } \\
\mu\left[\mathrm{s}^{-1}\right]\end{array}$ & $\begin{array}{l}\text { Frequency } \\
\quad v[\mathrm{~Hz}]\end{array}$ & $\begin{array}{l}\text { Damping } \\
\mu\left[\mathrm{s}^{-1}\right]\end{array}$ & $\begin{array}{l}\text { Frequency } \\
\quad v[\mathrm{~Hz}]\end{array}$ & $\begin{array}{l}\text { Damping } \\
\mu\left[\mathrm{s}^{-1}\right]\end{array}$ \\
\hline 150 & 95.1 & 29.9 & 90.2 & 31.3 & 87.2 & 33.1 \\
\hline 175 & 67.1 & 24.3 & 65.3 & 24.9 & 62.8 & 26.5 \\
\hline 200 & 51.2 & 18.9 & 49.8 & 20.1 & 48.1 & 21.0 \\
\hline 225 & 39.2 & 14.2 & 38.8 & 15.3 & 37.3 & 16.5 \\
\hline 250 & 33.1 & 12.1 & 31.3 & 12.8 & 29.8 & 13.7 \\
\hline
\end{tabular}

In Figure 15, we present the recording of vibrations (natural frequency and damping factor) in a sample of composite material with matrix of hybrid resin of type 2, reinforced with the second type of flax fabric, for a free length of $200 \mathrm{~mm}$.

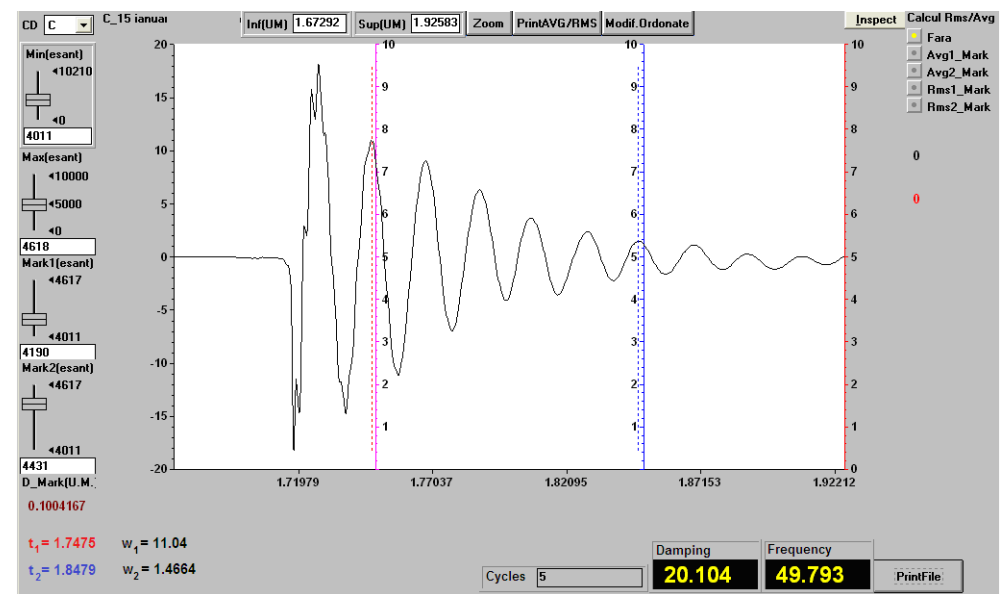

Figure 15. Recording of vibrations (natural frequency and damping factor) in a sample of hybrid resin of type 2, reinforced with the second type of flax fabric, for a free length of $200 \mathrm{~mm}$. 
In Table 8, we present you the behavior at vibrations of samples from materials for composites with matrix of hybrid resin of type 1, 2 and 3, reinforced with the second type of flax fabric. The presented values represent the arithmetic mean for three measurements.

Table 8. The behavior under vibrations of samples from composites with matrix of hybrid resin of type 1,2 and 3, reinforced with the second type of flax fabric.

\begin{tabular}{|c|c|c|c|c|c|c|}
\hline \multirow{2}{*}{$\begin{array}{c}\text { Free } \\
\text { Length } \\
{[\mathrm{mm}]}\end{array}$} & \multicolumn{2}{|c|}{$\begin{array}{l}\text { Composite Material with } \\
\text { Hybrid Resin of Type } 1\end{array}$} & \multicolumn{2}{|c|}{$\begin{array}{l}\text { Composite Material with } \\
\text { Hybrid Resin of Type } 2\end{array}$} & \multicolumn{2}{|c|}{$\begin{array}{l}\text { Composite Material with } \\
\text { Hybrid Resin of Type } 3\end{array}$} \\
\hline & $\begin{array}{c}\text { Frequency } \\
v[\mathrm{~Hz}]\end{array}$ & $\begin{array}{c}\text { Damping } \\
\mu\left[\mathrm{s}^{-1}\right]\end{array}$ & $\begin{array}{c}\text { Frequency } \\
v[\mathrm{~Hz}]\end{array}$ & $\begin{array}{c}\text { Damping } \\
\mu\left[\mathrm{s}^{-1}\right]\end{array}$ & $\begin{array}{c}\text { Frequency } \\
v[\mathrm{~Hz}]\end{array}$ & $\begin{array}{c}\text { Damping } \\
\mu\left[\mathrm{s}^{-1}\right]\end{array}$ \\
\hline 150 & 101.0 & 22.3 & 96.3 & 23.3 & 91.3 & 24.2 \\
\hline 175 & 73.4 & 17.7 & 70.6 & 18.1 & 65.9 & 18.9 \\
\hline 200 & 56.2 & 13.2 & 54.3 & 13.3 & 51.5 & 14.4 \\
\hline 225 & 43.4 & 10.0 & 42.1 & 10.6 & 40.6 & 11.4 \\
\hline 250 & 35.3 & 8.8 & 34.1 & 9.1 & 31.9 & 9.4 \\
\hline
\end{tabular}

The natural frequencies of the bars depend on not only the dimensions (thickness, length), but also on the material properties (density and modulus of elasticity).

Because the test samples studied had similar dimensions, the differences between the measured frequencies are due to the differences between the modulus of elasticity of the composite materials from which the samples are made.

We found that there is a correspondence between the measured frequencies and the modulus of elasticity determined at the tensile test, more precisely the increase of the modulus of elasticity leads to the increase of the vibration frequency. The damping factor as a whole characterizes the vibration damping capacity for a test piece. Comparison of the results in Tables 7 and 8 shows that the samples reinforced with the second type of fabric dampen the vibrations better. We also found that the vibration damping capacity increases with increasing volume ratio of Dammar in the hybrid resin used as a matrix.

\section{Discussion}

The use of natural resins for manufacturing composite materials is influenced by the properties of these resins and by their capacity of performing a synergetic effect together with the reinforcement materials. The analysis of the obtained results shows a significant variation of the hybrid resins properties studied depending on the ratio between the natural and synthetic resin. A quick decrease in the elasticity modulus is seen at the increase of the Dammar ratio in the structure of the hybrid resin, from $3077( \pm 92) \mathrm{MPa}$ for the hybrid resin of type 1, to $1798( \pm 45) \mathrm{MPa}$ for the hybrid resin of type 3. A decrease from $25.5( \pm 1.5) \mathrm{MPa}$ for hybrid resin of type 1 , to $13( \pm 1) \mathrm{MPa}$ for hybrid resin of type 3 can also be noticed. For the elongation at break, the effect is reverse, an increase is seen once as the Dammar volume ratio increases. Significant modifications can be seen in the form of the characteristic curve too. If in the case of the hybrid resin of type 1 the characteristic curve is almost linear, in the hybrid resin of type 3 the nonlinearity is significant.

For studied composite materials the comparison of experimental results shows a significant modification of the mechanical properties when the ratio between the epoxy resin and natural resins is changed. A decrease in values for the tensile strength and the elasticity modulus is seen as the volume ratio of natural resin from the mixture increases. The elongation at break, although it increases in the case of hybrid resins as the Dammar ratio increases, in the case of composites, it decreases as the Dammar ratio increases, regardless of reinforcing materials.

The analysis of the characteristic curves shows that three stages of the stress process stand out. In the first stage, we notice a proportionality between the normal tension and the specific deformation, so Hooke's law is applicable. Therefore, at this stage, we may consider that the stress is taken over uniformly by matrix and reinforcer. In the second stage, the composite material displays a nonlinear behavior, as the dependence between the normal tension and the specific deformation loses 
its proportionality character. In this stage, we may conclude the tensile tension reaches a maximum in the resin and, consequently, it may present breaks, tack losses between fibers and matrix, as well as wrenches of the fibers from the resin. Thus, there is a stress transfer to the fibers. If in the first stage and the beginning of the second one the stress is taken over by the whole composite material, at the end of the second stage the stress is mainly taken over by the fibers. In the third stage the dependence between the normal tension and the specific deformation becomes linear again, which can be explained by the stress being taken over by the fabric fibers only, which are longitudinally arranged, and the material break occurring when the fibers break up.

The behavior of composite materials is also confirmed by the images obtained using SEM analysis, which shows that the fibers, in the breaking area, are detached from the matrix. In addition, a higher fiber density is observed for the first type of flax fabric, which explains the superior properties of composites reinforced with this type of fabric.

The variations of tensile strengths, both for composites reinforced with the first type of fabric and for the composites reinforced with the second type of fabric, are smaller than the variations of tensile strengths for the used resins. If, for the hybrid resin, the maximum variations between the tensile strength of type 1 resin and the tensile strength of type 3 resin has been $15 \mathrm{MPa}$, in the composite materials, regardless of the reinforcing materials, this difference has been $9 \mathrm{MPa}$. In the case of the elasticity modulus of composite materials, these variations have been even smaller. If, for the hybrid resin, the maximum variation between the elasticity modulus of the hybrid resin of type 1 and elasticity modulus of hybrid resin of type 3 has been $1417 \mathrm{MPa}$, for the composites reinforced with the first type of fabric this variation has been $430 \mathrm{MPa}$, and for the composites reinforced with the second type of fabric the variation has been $330 \mathrm{MPa}$. This phenomenon can be explained by the fact that the stress has been taken from the beginning by fibers, the matrix having the role to support the fibers.

The properties of flax fibers are influenced not only by natural factors (climatic conditions, soil, seed varieties, etc.), but also by plant processing conditions. We can find, based on bibliographic data, that the mechanical properties of flax fibers (see [1,4]) are far superior to the mechanical properties of the hybrid resins studied by us. And in the case of studied composite materials, we found that the values of modulus of elasticity and those of tensile strength are much higher than those of hybrid resins used as matrices. Therefore, we can conclude that the two types of flax fabrics have a decisive influence in establishing their mechanical behavior. In addition, the elongation at break in composite materials reinforced with the two types of flax fabric is close to the elongation at break of flax fibers which is $2.7-3.2 \%$ (see $[1,4]$ ). Therefore, the breaking of the test pieces from the studied composite materials took place at the time of breaking the fibers.

Because the damping factor depends on the sample length, it characterizes the global capacity of the sample damping. In order to determine the capacity to damp vibrations in the studied composite materials, the loss factor can be calculated as $\eta=\frac{\mu}{\pi v}$ (see [48]) for each of the materials. For composite materials reinforced with the first type of flax fabric, the average value of the loss factor is:

- $\quad \eta=0.0749$ for composite with matrix of resin of type 1 ;

- $\quad \eta=0.0804$ for composite with matrix of resin of type 2;

- $\quad \eta=0.0895$ for composite with matrix of resin of type 3 .

For composite materials reinforced with the second type of flax fabric, the average value of the loss factor is:

- $\quad \eta=0.1129$ for composite with matrix of resin of type 1 ;

- $\quad \eta=0.1232$ for composite with matrix of resin of type 2;

- $\quad \eta=0.1363$ for composite with matrix of resin of type 3 .

The loss factor for composites reinforced with resin with type 3 is $20 \%$ higher than for the composites reinforced with resin of type 1 . Consequently, we obtain an increase in the capacity to damp vibrations, when there is an increase of the Dammar ratio in the composition. For the composite materials reinforced with the second type of fabric, the loss factor is $50 \%$ higher than for the composites 
reinforced with fabric of first type. This can be explained by the higher number of layers, but it can also be due to the differences of properties of the two types of fabrics. We notice that the damping factor is inversely proportional with the square of the free length of the bar. Since there is a similar dependence in the case of the own pulsations we may draw the conclusion that it is predominantly a mechanism of energy dissipation, where the damping force is proportional to the bending speed of the bar.

For the elongation at break, even though it increases in the case of hybrid resins when there is an increase in the Dammar ratio, in the case of composites, regardless of the reinforcing material, it decreases with the increase in the Dammar ratio. This shows that the composite break up when the break of fibers takes place.

Based on the list of peaks seen on the spectrum of the hybrid resin of type 2, we can determine the following groups and classes of chemical components:

- 2916-2870 $\mathrm{cm}^{-1}$ the elongation of aromatic and aliphatic $C-H$ bonds takes place (saturated systems of alkane type);

- $\quad 1450 \mathrm{~cm}^{-1}$ the elongation of aromatic $C-H$ bonds takes place (indicates the presence of methylene groups $\left.\left(\mathrm{CH}_{2}\right)\right)$;

- $\quad 1242 \mathrm{~cm}^{-1}$ the elongation of $\mathrm{C}-\mathrm{O}-\mathrm{C}$ bonds of ethers and esters takes place;

- $\quad 750 \mathrm{~cm}^{-1}$ indicates the presence of some strong bonds of $C-C 1$ type.

Comparing the spectrums of the three types of hybrid resin, we notice a mitigation of the absorption capacity only; no shrinking or movements of bands are observed, which suggest the lack of interaction between components.

\section{Conclusions}

The paper studied the mechanical properties of composite materials made of three types of hybrid resin based on Dammar reinforced with two types of flax fabric. We found that

1. for hybrid resins the modulus of elasticity and breaking strength decrease, and the elongation at break increases with increasing volume ratio of Dammar;

2. for composite materials both the modulus of elasticity, the breaking strength and the elongation at break decrease with increasing volume ratio of Dammar;

3. the studied composite materials have good vibration damping properties; the loss factor increases with increasing volume ratio of Dammar;

4. composites reinforced with the first type of flax fabric have better mechanical properties than composites reinforced with the second type of fabric, but have lower damping properties;

5. for all studied composites the damping factor is inversely proportional to the square of the bar length; this corresponds to an energy loss mechanism in which the damping force is proportional to the bending speed of the bar.

The properties of the studied composite materials show that they can be used successfully in:

- aeronautics for manufacturing some fuselage elements or movable empennage elements, flaps, and so on;

- construction of vehicles for manufacturing some bodywork elements, such as wings, doors, and so on;

- civil and industrial engineering for manufacturing some component elements of formworks as substitute for composite materials manufactured of synthetic components.

Author Contributions: Conceptualization, D.B. and M.M.S.; casting of samples and performed the experiments, M.M.S. and D.B.; analysis and interpretation of experimental data, D.B. and M.M.S.; methodology, M.M.S. and D.B.; writing—original draft, D.B. and M.M.S.; writing-review and editing, M.M.S. All authors have read and agreed to the published version of the manuscript.

Funding: This research received no external funding.

Conflicts of Interest: The authors declare no conflict of interest. 


\section{References}

1. Mohanty, A.K.; Misra, M.; Hinrichsen, G. Biofibers, biodegradable polymers and biocomposites: An overview. Macromol. Mater. Eng. 2000, 276-277, 1-24. [CrossRef]

2. Shogren, R.L.; Petrovic, Z.; Liu, Z.S.; Erhan, S.Z. Biodegradation behavior of some vegetable oil-based polymers. J. Polym. Environ. 2004, 12, 173-178. [CrossRef]

3. Uyama, H.; Kuwabara, M.; Tsujimoto, T.; Kobayashi, S. Enzymatic synthesis and curing of biodegradable epoxide-containing polyesters from renewable resources. Biomacromolecules 2003, 4, 211-215. [CrossRef]

4. Mohanty, A.K.; Misra, M.; Drzal, T.L. Natural Fibers, Biopolymers and Bocomposites; CRC Press Taylor \& Francis: London, UK, 2005; 896 p. [CrossRef]

5. Kanehashi, S.; Oyagi, H.; Lu, R.; Miyakoshi, T. Developement of bio-based hybrid resin, from natural lacquer. Prog. Org. Coat. 2014, 77, 24-29. [CrossRef]

6. Ishimura, T.; Lu, R.; Yamasaki, K.; Miyakoshi, T. Development of an eco-friendly hybrid lacquer based on kurome lacquer sap. Prog. Org. Coat. 2010, 69, 12-15. [CrossRef]

7. Drisko, G.L.; Sanchez, C. Hybridization in materials science-evolution, current state, and future aspirations. Eur. J. Inorg. Chem. 2012, 32, 5097-5105. [CrossRef]

8. Scalarone, D.; Duursma, M.C.; Boon, J.J.; Chiantore, O. MALDI-TOF mass spectrometry on cellulosic surfaces of fresh and photo-aged di- and triterpenoid varnish resins. J. Mass Spectrom. 2005, 40, 1527-1535. [CrossRef]

9. Echard, J.P.; Benoit, C.; Peris-Vicente, J.; Malecki, V.; Gimeno-Adelantado, J.V.; Vaiedelich, S. Gas chromatography/mass spectrometry characterization of historical varnishes of ancient Italian lutes and violin. Anal. Chim. Acta 2007, 584, 172-180. [CrossRef]

10. Li, X.; Tabil, L.G.; Panigrahi, S.; Crerar, W.J. The influence of fiber content on properties of injection molded flax fiber-HDPE biocomposites. In Proceedings of the CSBE/SCGAB 2006 Annual Conference, Edmonton, AL, Canada, 16-19 July 2006. [CrossRef]

11. Oksman, K. Mechanical properties of natural fibre mat reinforced thermoplastic. Appl. Compos. Mater. 2000, 7, 403-414. [CrossRef]

12. Mohanty, A.K.; Misra, M.; Drzal, L.T. Sustainable bio-composites from renewable resources: Opportunities and challenges in the green materials world. J. Polym. Environ. 2002, 10, 19-26. [CrossRef]

13. Sreekala, M.S.; Kumaran, M.G.; Thomas, S. Water sorption in oil palm fiber reinforced phenol formaldehyde composites. Compos. Part A Appl. Sci. Manuf. 2002, 33, 763-777. [CrossRef]

14. Sreekala, M.S.; Thomas, S. Effect of fibre surface modification on watersorption characteristics of oil palm fibres. Compos. Sci. Technol. 2003, 63, 861-869. [CrossRef]

15. Yan, L.; Chouw, N. Crashworthiness characteristics of flax fibre reinforced epoxy tubes for energy absorption application. Mater. Des. 2013, 51, 629-640. [CrossRef]

16. Yan, L.; Chouw, N.; Jayaraman, K. Lateral crushing of empty and polyurethane-foam filled natural flax fabric reinforced epoxy composite tubes. Compos. Part B Eng. 2014, 63, 15-26. [CrossRef]

17. Yan, L.; Chouw, N. Natural FRP tube confined fibre reinforced concrete under pure axial compression: A comparison with glass/carbon FRP. Thin-Walled Struct. 2014, 82, 159-169. [CrossRef]

18. Yan, L.; Chouw, N.; Jayaraman, K. Effect of triggering and polyurethane foam-filler on axial crushing of natural flax/epoxy composite tubes. Mater. Des. 2014, 56, 528-541. [CrossRef]

19. Yan, L.; Su, S.; Chouw, N. Microstructure, flexural properties and durability of coir fibre reinforced concrete beams externally strengthened with flax FRP composites. Compos. Part B Eng. 2015, 80, 343-354. [CrossRef]

20. Hidayat, A.T.; Farabi, K.; Harneti, D.; Maharani, R.; Mayanti, T.; Setiawan, A.S.; Supratman, U.; Shiono, Y. Cytotoxicity and structure activity relationship of Dammarane-type triterpenoids from the bark of aglaia elliptica against P-388 murine leukemia cells. Nat. Prod. Sci. 2017, 23, 291-298. [CrossRef]

21. Ukiya, M.; Kikuchi, T.; Tokunda, H.; Tabata, K.; Kimura, Y.; Arai, T.; Ezaki, Y.; Oseto, O.; Suzuki, T.; Akihisa, T. Antitumor-promoting effects and cytotoxic activities of Dammar resin triterpenoids and their derivatives. Chem. Biodivers. 2010, 7, 1871-1884. [CrossRef]

22. Jhala, A.J.; Hall, L.M. Flax (Linum usitatissimum L.): Current uses and future applications. Aust. J. Basic Appl. Sci. 2010, 4, 4304-4312. [CrossRef]

23. Kymäläinen, H.R.; Sjöberg, A.M. Flax and hemp fibers as raw materials for thermal insulations. Build. Environ. 2008, 43, 1261-1269. [CrossRef] 
24. Korniejenko, K.; Łach, M.; Hebdowska-Krupa, M.; Mikuła, J. The mechanical properties of flax and hemp fibers reinforced geopolymer composites. IOP Conf. Ser. Mater. Sci. Eng. 2018, 379, 012023. [CrossRef]

25. Sumaiya S. Fabrication and property evaluation of hemp-flax fiber reinforced hybrid composite. Chem. Mat. Eng. 2019, 7, 17-23. [CrossRef]

26. Van de Weyenberg, I.; Ivens, J.; De Coster, A.; Kino, B.; Baetens, E.; Verpoest, I. Influence of processing and chemical treatment of flax fibres on their composites. Compos. Sci. Technol. 2003, 63, 1241-1246. [CrossRef]

27. Van de Weyenberg, I.; Truong, T.C.; Vangrimde, B.; Verpoest, I. Improving the properties of UD flax fibre reinforced composites by applying an alkaline fibre treatment. Compos. Part A Appl. Sci. Manuf. 2006, 37, 1368-1376. [CrossRef]

28. Wu, C.M.; Lai, W.Y.; Wang, C.Y. Effects of surface modification on the mechanical properties of flax / $\beta$-Polypropylene composites. Materials 2016, 9, 314. [CrossRef]

29. Mazzanti, V.; Pariante, R.; Bonanno, A.; de Ruiz Ballesteros, O.; Mollica, F.; Filippone, G. Reinforcing mechanisms of natural fibers in green composites: Role of fibers morphology in a PLA/hemp model system. Compos. Sci. Technol. 2019, 180, 51-59. [CrossRef]

30. Huang, X.; Netravali, A. Characterization of flax fiber reinforced soy protein resin based green composites modified with nano-clay particles. Compos. Sci. Technol. 2007, 67, 2005-2014. [CrossRef]

31. Adekunle, K.; Cho, S.; Ketzscher, R.; Skrifvars, M. Mechanical properties of natural fiber hybrid composites based on renewable thermoset resins derived from soybean oil, for use in technical applications. J. Appl. Polym. Sci. 2012, 124, 4530-4541. [CrossRef]

32. Adekunle, K.; Cho, S.; Patzelt, C.; Blomfeldt, T.; Skrifvars, M. Impact and flexural properties of flax fabrics and Lyocell fiber-reinforced bio-based thermoset. J. Reinf. Plast. Compos. 2011, 30, 685-697. [CrossRef]

33. Lincoln, J.D.; Shapiro, A.A.; Earthman, J.C.; Saphores, J.M.; Ogunseitan, O.A. Design and evaluation of bioepoxy-flax composites for printed circuit boards. IEEE Transac. Electron. Packag. Manuf. 2008, 31, 211-220. [CrossRef]

34. Berger, C.; Bledzki, A.K.; Heim, H.; Böttcher, A. Fiber-reinforced epoxy composites made from renewable resources. In Proceedings of the 2011 International SAMPE Technical Conference, Fort Worth, TX, USA, 18-19 October 2011.

35. Felline, F.; Pappada, S.; Gennaro, R.; Passaro, A. Resin transfer moulding of composite panels with bio-based resins. SAMPE J. 2013, 49, 20-24.

36. Avril, C.; Bailly, P.A.; Njuguna, J.; Nassiopoulos, E.; de Larminat, A. Development of flax-reinforced bio-composites for high-load bearing automotive parts. In Proceedings of the European Conference on Composite Materials (ECCM), Venice, Italy, 24-28 June 2012.

37. Fan, J.; Nassiopoulos, E.; Brighton, J.; de Larminat, A.; Njuguna, J. New structural biocomposites for car applications. In Proceedings of the Society of Plastics Engineers-EUROTEC 2011 Conference, Barcelona, Spain, 14-15 November 2011.

38. Zhu, J.; Abhyankar, H.; Nassiopoulos, E.; Njuguna, J. Tannin-based flax fiber reinforced composites for structural applications in vehicles. IOP Conf. Ser. Mater. Sci. Eng. 2012, 40, 1-8. [CrossRef]

39. Pizzi, A.; Kueny, R.; Lecoanet, F.; Massetau, B.; Carpentier, D.; Krebs, A.; Loiseau, F.; Molina, S.; Ragoubi, M. High resin content natural matrix-natural fiber biocomposites. Ind. Crops Prod. 2009, 30, 235-240. [CrossRef]

40. Zhu, J.; Njuguna, J.; Abhyankar, H.; Zhu, H.; Perreux, D.; Thiebaud, F.; Chapelle, D.; Pizzi, A.; Sauget, A.; de Larminat, A.; et al. Effect of fiber configurations on mechanical properties of flax/tannin composites. Ind. Crop. Prod. 2013, 50, 68-76. [CrossRef]

41. Sharma, P.; Mittal H.; Jindal, R.; Jindal, D.; Alhassan, S.M. Sustained delivery of atenolol drug using gum Dammar crosslinked polyacrylamide and zirconium based biodegradable hydrogel composites. Collid Surf. A 2019, 562, 136-145. [CrossRef]

42. Sharma, P.; Jindal, R.; Maiti, M.; Jana, A.K. Novel organic-inorganic composite material as a cation exchanger from a triterpenoidal system of dammar gum: Synthesis, characterization and application. Iran Polym. J. 2016, 25, 671-685. [CrossRef]

43. Sharma, P.; Jindal, R.; Maiti, M. Studies on gum Dammar based composite ion exchanger and their characterization. Polym. Bull. 2018, 75, 1365-1385. [CrossRef]

44. Sharma, P.; Jindal, R. Gum Dammar and poly(acrylamide)-based hydrogels and zirconium-based organic-inorganic hybrid materials for controlled drug delivery and their biodegradation studies. Polym. Bull. 2018, 75, 4175-4190. [CrossRef] 
45. Pethe, A.M.; Joshi, S.B. Physicomedical, mechanical and film forming studies of novel biomaterial. Int. J. Pharm. Sci. Res. 2013, 4, 2761-2769. [CrossRef]

46. Zakaria, R.; Ahmad, A.H. Adhesion and hardness evaluation of modified silicone-Dammar as natural coating materials. Am. J. Appl. Sci. 2012, 9, 890-893. [CrossRef]

47. Zakaria, R.; Ahmad, A.H. The performance of modified silicone-Dammar resin in nanoindentation test. Int. J. Adv. Sci. Technol. 2012, 42, 33-44. [CrossRef]

48. Stănescu, M.M.; Bolcu, D. A study of some mechanical properties of a category of composites with a hybrid matrix and natural reinforcements. Polymers 2019, 11, 478. [CrossRef]

49. Bolcu, D.; Stănescu, M.M. The influence of non uniformities on the mechanical behavior of hemp-reinforced composite materials with a Dammar matrix. Materials 2019, 12, 1232. [CrossRef]

50. S.C. VITAL NET MED S.R.L., Bucharest, Romania. Available online: www.foitadeaur.ro/rasini.htm (accessed on 3 February 2020).

51. S.C. DINATEX S.R.L., Falticeni, Suceava, Romania. Available online: http://dinatex.3x.ro/ (accessed on 18 January 2020).

52. Resoltech 1050, Hardeners 1053 to 1059. Structural Lamination Epoxy System. Available online: www.scabro. com/images /.../1/.../Resoltech\%201050/DS-1050.pdf (accessed on 3 February 2020).

53. ASTM D3039, Standard Test Method for Tensile Properties of Polymer Matrix Composite Materials. Available online: https:/ / www.astm.org/Standards/D3039 (accessed on 3 February 2020).

54. Kabir, M.M.; Wang, H.; Lau, K.T.; Cardona, F. Chemical treatments on plant-based natural fibre reinforced polimer composite: An overview. Compos. Part B Eng. 2012, 43, 2883-2892. [CrossRef]

55. Ho, M.P.; Wang, H.; Lee, J.H.; Ho, C.K.; Lau, K.T.; Leng, J.; Hui, D. Critical factors on manufacturing processes of natural fibre composites. Compos. Part B Eng. 2012, 43, 3549-3562. [CrossRef]

56. LLOYD LRX PLUS SERIES, Materials Testing Machine. Available online: http://www.elis.it/lloyd-pdf/ LRXPlus.pdf (accessed on 3 February 2020).

57. ASTM E168, Standard Practices for General Techniques of Infrared Quantitative Analysis. Available online: https:/ / www.astm.org/Standards/E168.htm (accessed on 3 February 2020).

58. ASTM E1252, Standard Practice for General Techniques for Obtaining Infrared Spectra for Qualitative Analysis. Available online: https://www.astm.org/Standards/E1252.htm (accessed on 3 February 2020).

59. IdentifyIR (FT-IR Analysis System). Technical Information. Available online: http:/ /www.betatekinc.com/ pdf/smiths_detection_identifyir.pdf (accessed on 3 February 2020).

60. Hitachi Model S-3400N (Type II), PC-Based Variable Pressure Scanning Electron Microscope. Available online: www.ntnu.edu/documents/140082/1269041159/S-3400NSpecifications.pdf/6b94c26fa9d4-4f36-82b3-7e9eb3603922 (accessed on 3 February 2020).

61. ASTM E1508, Standard Guide for Quantitative Analysis by Energy-Dispersive Spectroscopy. Available online: https:/ / www.astm.org/Standards/E1508.htm (accessed on 3 February 2020).

62. Franz, M.H.; Neda, I.; Maftei, C.V.; Ciuca, I.; Bolcu, D.; Stănescu, M.M. Studies of chemical and mechanical properties of hybrid composites based on natural resin Dammar formulated by epoxy resin. Polym. Bull. 2020. [CrossRef]

63. Sayyad, A.S. Comparison of various shear deformation theories for the free vibration of thick isotropic beams. Int. J. Civ. Struct. Eng. Res. 2011, 2, 85-97.

64. Hermann, L. Vibration of the Euler-Bernoulli beam with allowance for dampings. In Proceedings of the World Congress on Engineering 2008 (WCE 2008), London, UK, 2-4 July 2008; Volume II.

65. Kumar, N.; Singh, S.P. Vibration and damping characteristics of plat-bands with active constrained layer treatments under parametric variations. Mater. Design. 2009, 30, 4162-4174. [CrossRef]

66. Kulkarni, P.; Bhattacharjee, A.; Nanda, B.K. Study of damping in composite beams. Materialstoday Proc. 2018, 5, 7061-7067. [CrossRef]

67. Orban, F. Damping of materials and members in structures. In Proceedings of the 5th International Workshop on Multi-Rate Processes and Hysteresis (MURPHYS 2010), Pecs, Hungary, 31 May-3 June 2010; Article No. 268

68. Sarlin, E.; Liu, Y.; Vippola, M.; Zogg, M.; Ermanni, P.; Vuornien, J.; Lepisto, T. Vibration damping properties of steel/rubber/composite hybrid structures. Compos. Struct. 2012, 94, 3327-3335. [CrossRef] 
69. Bowyer, E.P.; Krylov, V.V. Experimental investigation of damping flexural vibrations in glass fibre composite plates containing one and two dimensional acoustic black holes. Compos. Struct. 2014, 107, 406-415. [CrossRef]

70. Yang, J.; Xiong, J.; Ma, L.; Zhang, G.; Wang, X.; Wu, L. Study on vibration damping of composite sandwich cylindrical shell with pyramidal truss-like cores. Compos. Struct. 2014, 117, 362-372. [CrossRef]

71. Vanwalleghem, J.; De Baere, I.; Loccufier, M.; Van Paepegem, W. External damping losses in measuring the vibration damping properties in lightly damped specimens using transient time-domain methods. J. Sound Vib. 2014, 333, 1596-1611. [CrossRef]

(C) 2020 by the authors. Licensee MDPI, Basel, Switzerland. This article is an open access article distributed under the terms and conditions of the Creative Commons Attribution (CC BY) license (http://creativecommons.org/licenses/by/4.0/). 